\title{
A critical review of the use of 3-D printing in the construction industry
}

\section{Abstract} industry.

3-D printing, which is an automated production process with layer-by-layer control, has been gaining rapid development in recent years. The technology has been adopted in the manufacturing industry for decades and has recently been introduced in the construction industry to print houses and villas. The technology can bring significant benefits to the construction industry in terms of increased customization, reduced construction time, reduced manpower and construction cost. A few isolated products and projects have been preliminarily tested using the 3-D printing technology. However, it should be noted that such tests and developments on the use of 3-D printing in the construction industry are very fragmented at the time of the study. It is therefore necessary for the building and construction industry to understand the technology, its historical applications and challenges for better utilization in the future. A systematic review shows that 3-D printing technology, after years of evolution, can be used to print large-scale architectural models and buildings. However, the potential of the technology is limited by the lack of large-scale implementation, the development of building information modelling, the requirements of mass customization and the life cycle cost of the printed projects. It is therefore expected that future studies should be conducted on these areas to consolidate the stability and expand the applicability of 3-D printing in the construction

Keywords: 3-D printing; construction industry; mass customization; building information modelling; life cycle cost.

\section{Introduction}

The construction industry has been recognized as one industry that consumes considerable amount of resources and poses significant environmental stresses. According to Klotz et al. (2007), buildings consumed 36 percent of the total energy used, 30 percent of the raw materials used and 12 percent of potable water consumed in the US. The industry has also been challenged for poor performance on productivity. For example, Nasir et al. (2014) compared the labour productivity of 20 countries and found that the US showed the worst performance with an annual compound rate of $-0.84 \%$. The low productivity issue has also been found in other developed countries, such as UK (Abdel-Wahab et al., 2008), Singapore (Lim and Alum, 1995) and Hong Kong (Lo et al., 2006). 
Over the past few decades, studies on construction innovations have been conducted to address the productivity, environmental and other issues in terms of two forms. One form of construction innovations is a response to external needs (e.g. the clients' needs) and the other form of construction innovations originates from other industries (Harty, 2008). However, as Tidd et al. (1997) pointed out, the main emphasis for innovation strategy in the construction industry is to use technology from elsewhere to reinforce other competitive advantages. This is one of the reasons why the construction industry is viewed as a low-tech industry with low levels of innovation (Harty, 2008).

The image of the construction industry may be changed as the industry has been actively participating in the 3-D printing business. According to Berman (2012), 3-D printing employs an additive manufacturing process whereby products are built on a layer-by-layer basis, through a series of cross-sectional slices. The term 3-D printing can also be applied to office or consumer versions of rapid prototyping machines that are relatively low-cost and easy to use (Casey, 2009). The global 3-D printing materials market value was US\$165m in 2013 and is expected to increase at a rate of $20 \%$ per year to US $\$ 410 \mathrm{~m}$ in 2018 (TechNavio, 2014). From the construction point of view, buildings are also products that have the potential to host 3-D printing. There have been many attempts in the construction industry to use 3-D printing to increase customisation, reduce construction time and improve affordability. For example, major contractors (such as Foster and Partners in London, UK) now have a suite of modelling equipment and 3-D printing process to print 3-D architectural models (Buswell et al., 2006). Other than creating 3-D models, 3-D printing has also evolved to produce large $(>1 \mathrm{~m})$ structures using contour crafting, which extrudes the internal and external skins of the wall that are later backfilled with a bulk compound similar to concrete (Khoshnevis, 2004).

However, it should be noted that the research relating to the application of 3-D printing in the construction industry is still in its infancy. Many new experiments have been conducted in the construction industry to explore the full potential that 3-D printing can bring to the construction industry. However, these experiments are very fragmented. A critical review of the history and current development of 3-D printing in the construction industry is therefore needed. This paper therefore aims to: (1) review the concept and characteristics of 3-D printing in the construction industry; (2) review the applications of 3-D printing in the construction industry; and (3) discuss the challenges of using 3-D printing in the construction industry and hope that by addressing these challenges, better utilization of the technology in the future can be expected. \\ 2. The definition and characteristics of 3-D printing in the construction industry}

According to Bogue (2013), 3-D printing is an automated, additive manufacturing process for producing 3-D solid objects from a digital (i.e. CAD) model. In other words, in a 3-D printing process, the 3-D CAD model will be sliced into a series of 2-D layers, which will later be deposited by the printer to construct the model.

Depending on the technologies used in the 3-D printing process, there are five main types of 3-D printing processes. The first type of technology is called stereolithography, which usually 
includes a perforated platform, a container of a liquid UV-curable polymer and a UV laser (Melchels et al., 2010). Based on the layers extracted from the CAD model, a beam of laser is used to trace the bottom layer of the model on the surface of the liquid UV-curable polymer, which will cause the polymer to harden. The perforated platform will then be lowered and the second layer will be traced and hardened by another beam of laser. The process will be repeated until the 3-D model is created (see Figure 1). According to Kang and Cho (2012), the development of suitable and affordable resin materials for stereolithography is a main barrier to implementing the technology as the current photo-curable resin costs from $\$ 80$ to $\$ 210$ per 87 litre.

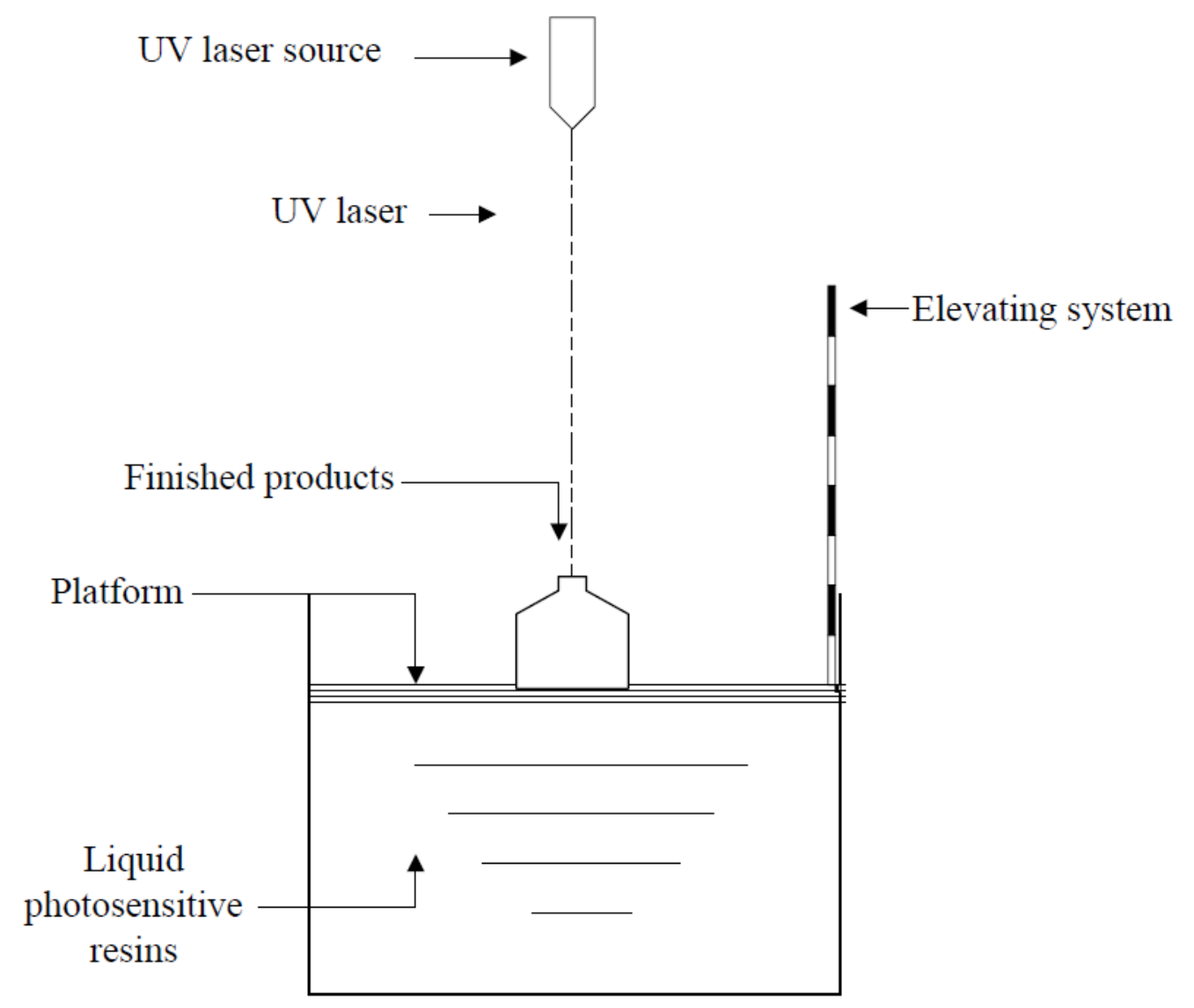

88

89 Figure 1. An illustration of the components and processes in stereolithography.

90 The second type of 3-D printing technology is usually referred to as fused deposition modelling 91 (FDM). It has three components: a printer head, printing material (e.g. polymers and synthetic 92 stone) and support material. Printing material is firstly fed to the printing head, which will later 93 moves in X-and Y-coordinates to deposit the material to print the first layer of model extracted 94 from the CAD model. Similar to stereolithography, the base will then move down for the printer 95 head to work on the second and other layers. Once completed, support material will be removed 96 (see Figure 2). In recent years, metals can be used as the print material in FDM. However, the 97 main disadvantages are the limitation of the material to low-temperature and low-strength alloy 


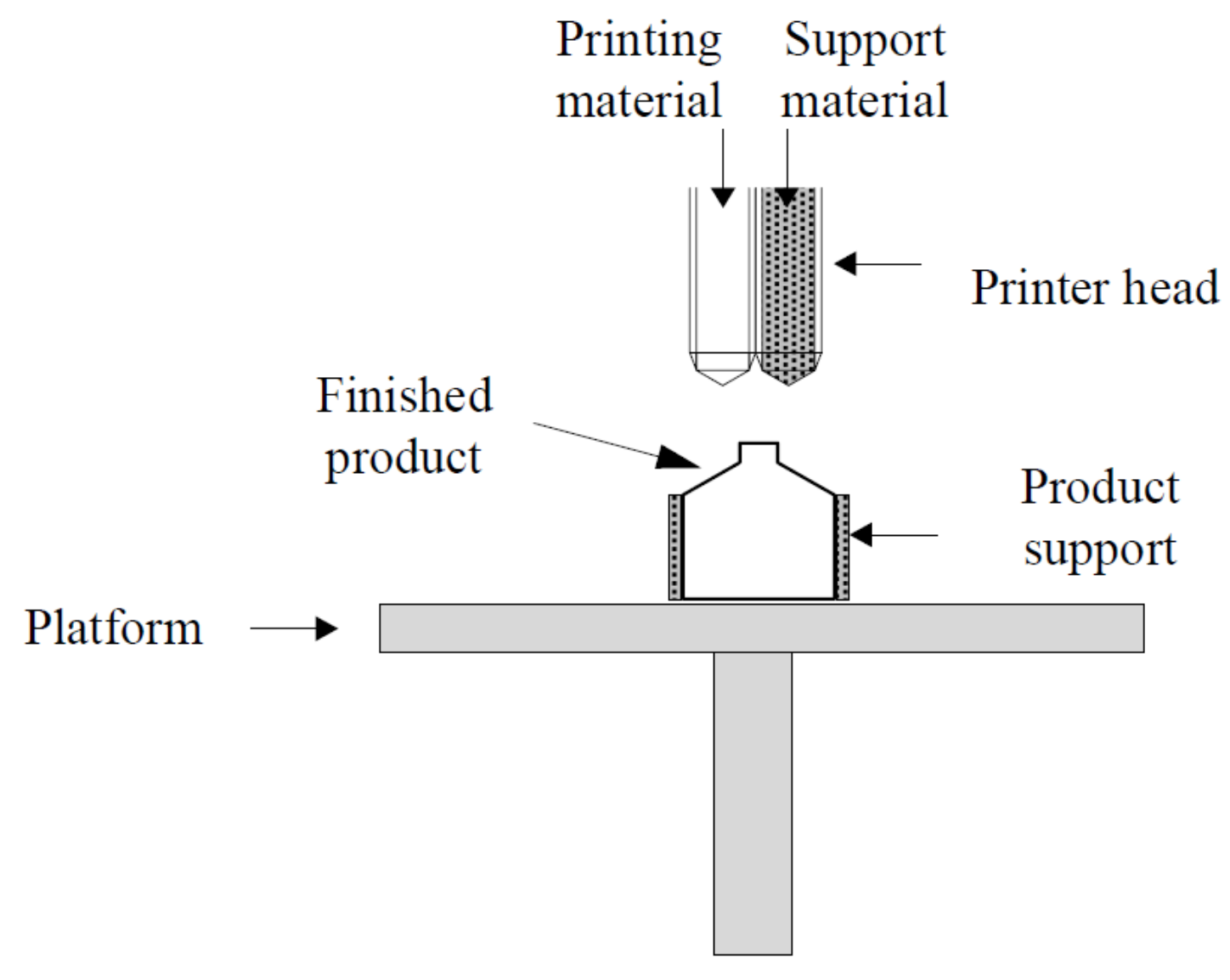

Figure 2. An illustration of the components and processes in FDM.

102 Another type of 3-D printing process is usually referred to as inkjet powder printing process

103 which uses glue or binder to bond successive powder layers together. Inkjet powder printing 104 can use metal as the printing material. Metal (e.g. steel or bronze) in the powder form is 105 deposited in the first layer. The printer head will spray binder material which will then be 106 heated and dried by a lamp (de Gans, 2004). When all layers are printed, the product will be 107 cured in an oven (see Figure 3). According to Castrejon-Pita et al. (2013, p.546), the main 108 barrier to implementing inkjet method is the requirement for an ink (i.e. the printing material) 109 that is safe to ingest, has no odour, low migration of monomers and other components, 110 satisfactory abrasion resistance for the packaging and distribution process, ability to heat seal, 111 pierce and die-cut without chipping, while still providing the intense colours and high 112 definition needed for primary retail packaging on a supermarket shelf. 


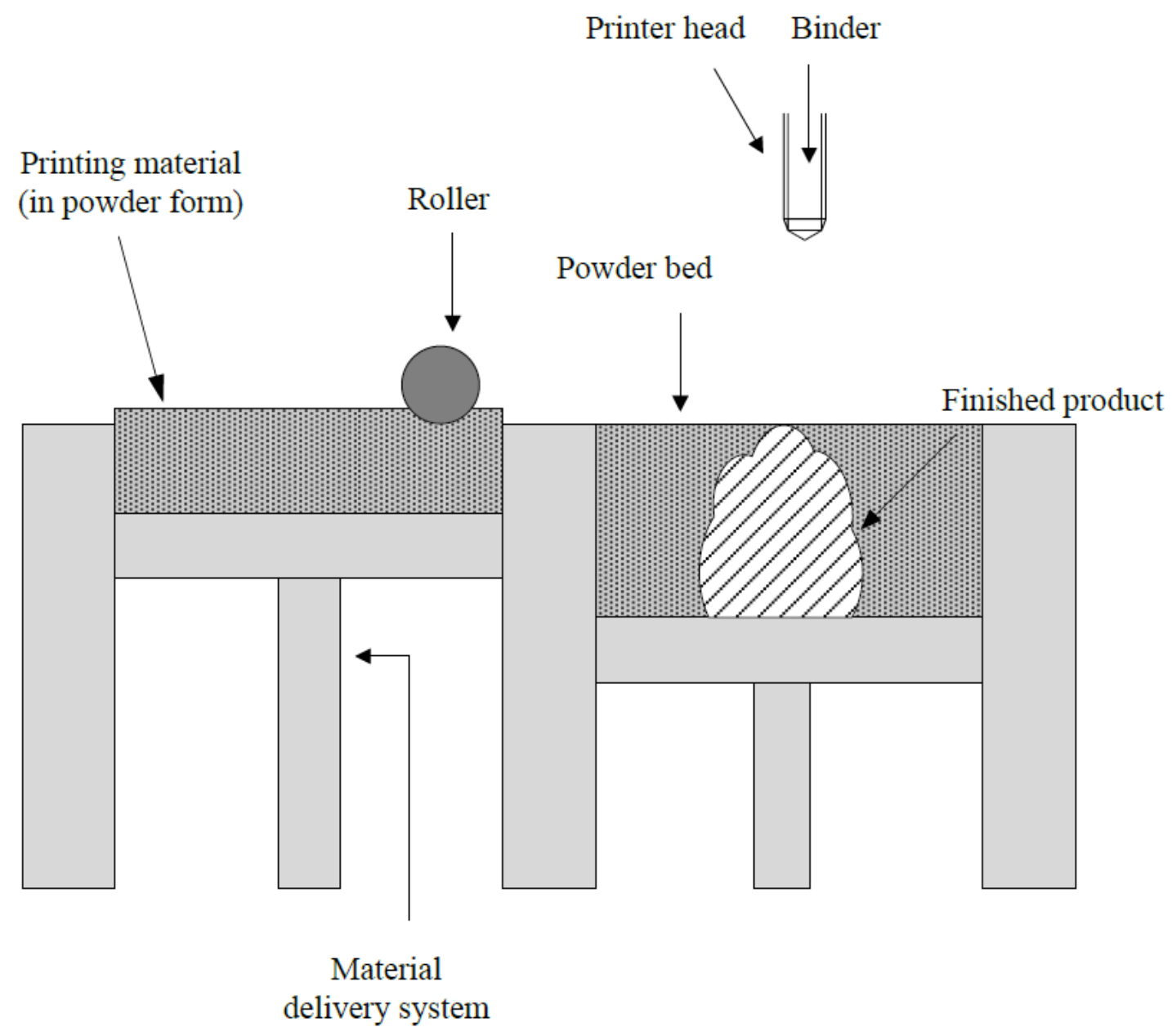

113

114 Figure 3. An illustration of the components and processes in inkjet powder printing.

115 Selective laser sintering (SLS) is a layer manufacturing process that allows generating complex

116 3-D parts by consolidating successive layers of powder material on top of each other (Kruth et

117 al., 2005). In SLS, the consolidation process is conducted using a focused laser beam. When

118 SLS is used to produce metal products, the process is usually referred to as selective laser

119 melting (SLM) or direct metal laser sintering (DMLS) (Kruth et al., 2004). For example, in the

120 SLM process, the metal powders are completed molten by the laser beam. As such, the printed

121 products have much higher density than the products printed by SLS (see Figure 4). Although

122 SKS and SLM are able to print high-strength product, these technologies face challenges

123 include temperature sensitivity and print size. To avoid oxidation of materials during the

124 printing process, the material fusing temperature should be hold to just below its melting point

125 (Kamrani and Nasr, 2010). In addition, the print size is usually small when using SLS. 


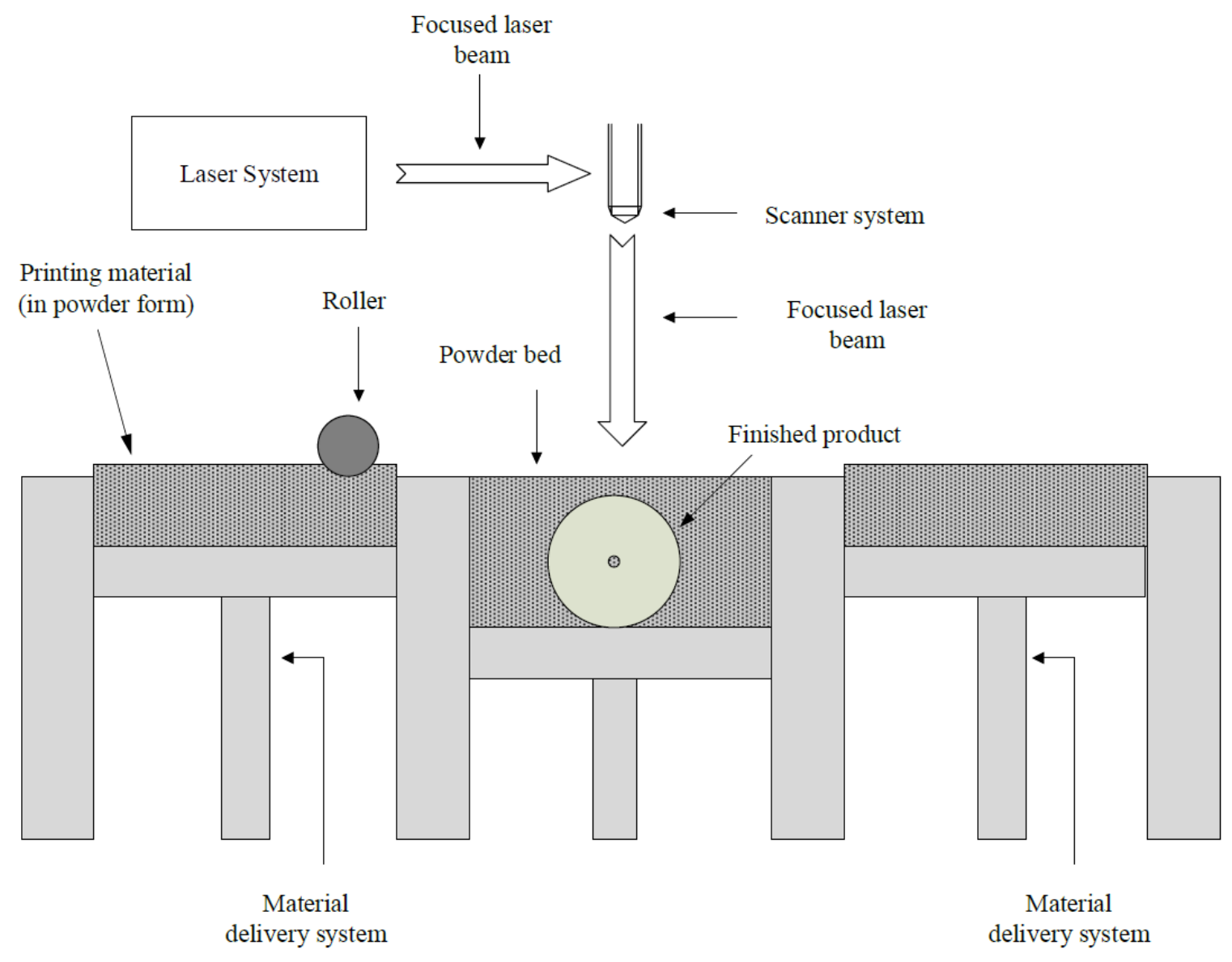

Figure 4. An illustration of the components and processes in SLS.

128 The latest 3-D printing technology developed for the construction industry is contour crafting,

129 which is an additive fabrication technology that uses computer control to exploit the superior 130 surface-forming capability of towelling to create smooth and accurate planar and free-form 131 surfaces (Khoshnevis, 2004). A complete contour crafting system includes a gantry system and 132 a nozzle. The gantry system used in contour crafting system is very similar to the gantry system 133 used in precast concrete fabrication. While on-site employees are usually required in precast 134 concrete production to ensure that the concrete-discharge system works appropriately and 135 formworks are dismantled at the end of the production stage, they are not required in contour 136 crafting because the process is computer-controlled. When the printing material is extruded 137 from the nozzle, it is troweled using a set of actuated and computer controlled trowels. A simple 138 illustration of the nozzle and trowels used in contour crafting is shown in Figure 5. According 139 to (Khoshnevis et al., 2001), one main challenge of contour crafting is to maintain uniform 140 level of viscosity, which will facilitate a smoother surface finish and improved structural 141 strength. 


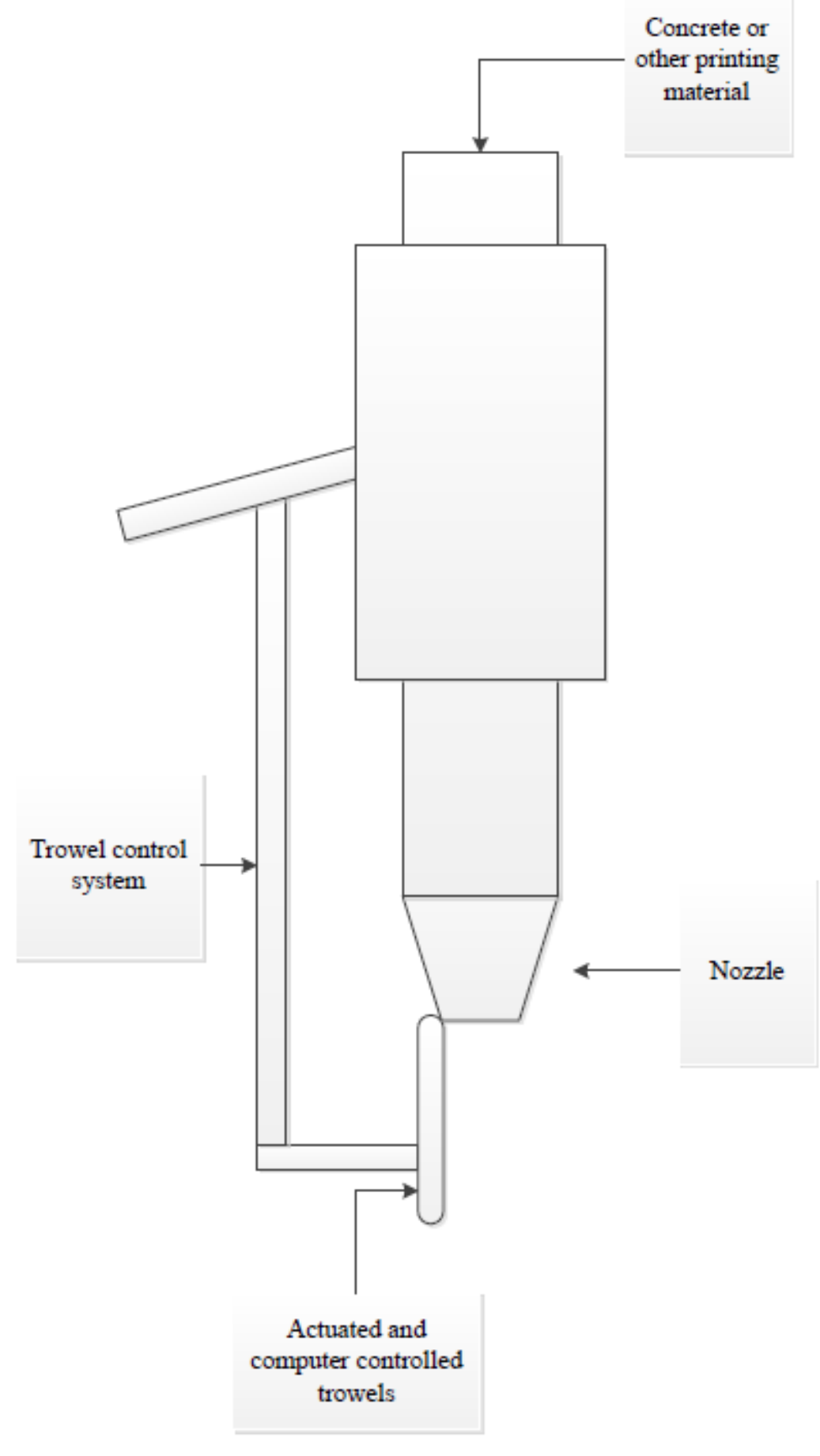

142

143 Figure 5. An illustration of the components and processes in contour crafting.

144 Table 1 summarizes the components, printing processes and some general characteristics of 145 different 3-D printing technologies. 


\begin{tabular}{|c|c|c|c|c|c|c|}
\hline $\begin{array}{l}\text { 3-D printing } \\
\text { technologies }\end{array}$ & Components & The printing process & $\begin{array}{c}\text { Cost } \\
\text { index }\end{array}$ & $\begin{array}{l}\text { Printing } \\
\text { time index }\end{array}$ & $\begin{array}{c}\text { Smallest } \\
\text { feature }^{3} \\
(\mu \mathrm{m})\end{array}$ & $\begin{array}{l}\text { Printing } \\
\text { materials }\end{array}$ \\
\hline Stereolithography & $\begin{array}{l}\text { - } \\
\text { - } \\
\text { A container of a liquid UV- } \\
\text { curable polymer } \\
\text { - } \quad \text { A UV laser }\end{array}$ & $\begin{array}{l}\text { Using a bean of UV laser to harden the } \\
\text { liquid polymer and lower the platform to } \\
\text { create multiple layers. }\end{array}$ & $200-400$ & $100-120$ & $1-366$ & $\begin{array}{l}\text { Liquid photosensitive } \\
\text { resins }\end{array}$ \\
\hline $\begin{array}{l}\text { Fused deposition } \\
\text { modelling }\end{array}$ & $\begin{array}{ll}\text { - } & \text { A printer head } \\
\text { - } & \text { Printing material } \\
\text { - } & \text { Support material } \\
\end{array}$ & $\begin{array}{l}\text { Printing material is fed to the printer } \\
\text { head to deposit the material to the layers. }\end{array}$ & 100 & 100 & $260-700$ & $\begin{array}{c}\text { Acrylonitrile butadiene } \\
\text { styrene (ABS); Elastomer; } \\
\text { Wax; Metal } \\
\end{array}$ \\
\hline $\begin{array}{l}\text { Selective laser } \\
\text { sintering and } \\
\text { Selective heating } \\
\text { sintering }\end{array}$ & $\begin{array}{l}\text { - } \quad \text { Focused laser beam } \\
\text { - Printing material in the } \\
\text { powder form }\end{array}$ & $\begin{array}{l}\text { Printing material in the poser form is } \\
\text { deposited. It is then consolidated using a } \\
\text { focused laser beam. The process is } \\
\text { repeated from layer to layer. }\end{array}$ & $200-400$ & $100-120$ & $45-100$ & $\begin{array}{l}\text { Nylon based materials; } \\
\text { Rapid steel; Sand form }\end{array}$ \\
\hline
\end{tabular}

1. The cost index is calculated based on various studies, including Ryder et al. (2002). The cost index does not provide detailed cost per unit of measurement. It provides a rough comparison of the printing cost of a single baby pushchair handle based on different 3-D printing technologies.

2. The printing time index (excluding contour crafting) does not provide detailed cost per unit of measure. It provides a rough comparison of the printing time of a single baby pushchair handle based on different 3-D printing technologies.

3. The smallest feature refers to the use of the technology in printing bone tissue as shown in Butscher et al. (2011). The smallest feature is used as a measurement of accuracy. 
148 As can be seen from Table 1, the selection of appropriate 3-D printing technology is dependent on the cost, printing time, accuracy and available materials. For the printing of metal-based objectives, both inkjet powder printing, FDM and SLS can be used as the printing technology. SLS has inherent advantage on product strength. On the other hand, for printing ceramics materials and concrete, contour crafting is usually used as the printing technology. In addition, the printing accuracy varies across different printing technologies. For the printing of lowaccuracy objects (e.g. architectural models for demonstration), inkjet powder printing can be selected. As low accuracy is needed, using inkjet powder printing will reduce the printing time. On the other hand, if high accuracy is needed (e.g. for objectives that have medical applications), stereolighography and SLS can be adopted. Similarly, as high accuracy is needed, the printing time will be increased correspondingly. Selecting the most economical 3-D printing technology will also depend on the accuracy requirement. As can be seen in Table 1, for the printing of low-accuracy objects, inkjet powder printing seems to be the most economical method with the lowest printing time and cost index. On the other hand, for the printing of high-accuracy objects, SLS and SLM seem to be the most economical method.

Other 3D printing technologies have also been developed in recent years to accommodate the need of the construction industry, especially in concrete printing. For example, the research team at the Loughborough University has developed a concrete printing process (which is referred to as Concrete Printing). A process called D-Shape has also been developed by straining a binder on the material layer (Monolite, 2015). D-shape is a factory gantry-based powder-bed 3D printer, which can print up to $6 \mathrm{~m}$ x $6 \mathrm{~m}$ x $6 \mathrm{~m}$ of architectural structures (Kreiger et al., 2015). The three technologies are designed for concrete printing and have many similarities in terms of the printing process. All printing technologies are based on additive manufacturing. However, each technology has distinct features. Similar to Contour Crafting, Concrete Printing uses the extrusion of cement mortar. However, compared to Contour Crafting, the technology has a smaller resolution of deposition (4-6mm in terms of layer depth), which allows for greater control of internal and external geometries (Lim et al., 2012). The compressive strength of the printed products by Concrete Printing can reach 100 to $110 \mathrm{MPa}$. On the other hand, the D-Shape process uses a powder deposition process, which is quite similar to the inkjet powder printing process where binder is used so that selective layers of printing materials are hardened. According to Lim et al. (2012), the compressive strength of the printed products can reach 235-242MPa. In addition, a 3D printing process, C-Fab (Cellular Fabrication), was designed by Branch Technology to print the support structure of construction walls, with the assistance of the Kuka robotic arm (Molitch-Hou, 2015). According to MolitchHou (2015), the Kuka robotic arm is only used to print the original support structure. Insulating foam is sprayed as the interior wall while concrete is applied as the exterior of the wall.

184 3-D printing can bring significant changes to the construction industry. It enables mass production without compromising customisation. Mass customization (i.e. building products to meet customers' individual orders rather than for stock) has been a goal for the construction industry for many decades (Barlow et al., 2003). There have been many attempts to achieve mass customization, including using prefabricated products. However, in order to reduce the costs associated with complexity, prefabricated components are usually standardized and only 
limited types of prefabricated products can be chosen. 3-D printing technology, on the other hand, can help build customized products with no increased costs as printing a complex building works the same way as printing a concrete block (Khoshnevis et al., 2001a; Khoshnevis et al., 2001b; Khoshnevis, 2004). With the streamlined printing process, 3-D printing can bring significant productivity improvement in terms of:

- Reduced waste. The 3-D printing process uses little more material than the object requires (Bak, 2003);

- Design flexibility. The 3-D printing process enables developers to design structures that are difficult to produce using the current manual construction practice (Khoshnevis, 2004).

- Reduced manpower. As most 3-D printing process is highly automated, manpower required in the construction process can be significantly reduced.

- Other economic, environmental and constructability-related improvements. Construction time can be greatly reduced using 3-D printing technologies. For example, the printing time for a structural wall was reduced to 65 hours from 100 hours by 3-D printing (Buswell et al., 2007). As only the required amount of materials will be needed, the printing process will eliminate unnecessary waste of materials, thus reducing the environmental impacts of the production/construction process.

\section{The history of the use of 3-D printing in the construction industry}

\subsection{3-D printing and construction parts}

Traditionally, the use of 3-D printing was restricted to the manufacturing sector. It was used to produce prototypes with low production volumes, small part sizes and complex designs (Berman, 2012). As such, the 3-D printing technology was usually referred to as Rapid Prototyping (RP) technology during that time. The first 3-D printer, using stereolithorgraphy technology, was developed by Charles Hull in 1986 (Hull, 1986). In the following years, other RP technologies have also been introduced into the market. For example, both SLS and FDM were introduced into the market in 1989. At this stage, RP technologies were used to produce prototypes for products mainly used in the manufacturing sector. For example, Arthur et al. (1996) used RP technology to produce electrical discharge machining electrodes. The technology continued to play an important role in the manufacturing industry in the $21^{\text {st }}$ century. Vinodh et al. (2009) investigated the adoption of 3-D printer to produce the prototype of a knob of an electronics switch. By using 3-D printing, it is believed that the capabilities of rapid prototyping can be merged with the high-volume throughput of conventional manufacturing (Bak, 2003).

While the use of RP technologies was mainly restricted to the manufacturing sectors, there were a few attempts that used construction-related materials which demonstrated the applicability of the technologies in the construction industry. For example, Hinczewski et al. (1998) used stereolithography to produce ceramic three-dimensional parts. A complex ceramic part was produced using stereolithography although the mechanical properties of the part were not optimized (Hinczewski et al., 1998). Similarly, Khoshnevis et al. (2001) used contour 
crafting and demonstrated that it could be used to produce plaster part if forced drying by heating was adopted. The research team at Loughborough University has taken an initiative to develop a 3D concrete printing process that can produce freeform building element. These pilot studies demonstrated that 3-D printing technologies could be used to produce construction components as long as appropriate quality control strategies were adopted.

As technology improved, the use of 3-D printing has been expanded to construction products other than ceramic products in recent years. For example, 3-D printers (e.g. RedDot - FDM Nylon 12 developed by Stratasys) can now print plastic and nylon items which are commonly used as plug fixtures, window frame fixtures and plumbing fittings in building projects. More importantly, concrete printing has been proven to be feasible in printing geometrically complicated concrete products (Lim et al., 2012). The size of the concrete products was limited using 3-D printing. For example, the 3-D printer in Lim et al. (2012) could only handle a print dimension up to $5.4 \mathrm{~m}(\mathrm{~L})$ x $4.4 \mathrm{~m}(\mathrm{~W})$ and $5.4 \mathrm{~m}(\mathrm{H})$. However, such size would produce enough capacity to print basic precast concrete components, such as the precast concrete column used in $\mathrm{Wu}$ and Low (2011). As such, the central issue relating to the use of 3-D printers in smallscale construction projects to produce construction parts is not related to the size, but rather whether there are enough flexibility and customization demands that can support the use of such technology to achieve economies of scale.

\subsection{3-D printing and architectural models}

249 The construction industry has adopted 3-D printing to produce architectural models since the early 2000s. Various 3-D printing technologies have been tested for their stability in printing architectural models. For example, Gibson et al. (2002) used RP technology to produce both geometrically simple and complicated architectural models. While the use of FDM printing caused the collapse of one architectural model, SLS has been proven to have the capacity to produce strong models (Gibson et al., 2002). The technology was useful to produce physical 3-D models quickly. The printing process could be completed within hours. Depending on the accuracy required in the architectural models, there were different 3-D printing technologies that could be used to produce architectural models.

The first set of technologies that could be used to produce low-accuracy architectural models was referred to as concept modelling (Ryder et al., 2002). One of the most highly recognized product in concept modelling is the 3-D Printer (3DP) process developed by the Massachusetts Institute of Technology (MIT). The detailed information for every layer was firstly generated by using a computer model. Powder materials and binding materials were then applied from

263 layer to layer before a final step of heat treatment was conducted (MIT, 2000). Concept modelling could produce architectural models within a quick time frame.

RP technologies, including FDM, SLS and stereolithography, were later introduced into the construction industry to produce architectural models. The accuracy of these technologies was improved to $0.1 \mathrm{~mm}-0.2 \mathrm{~mm}$ compared to the accuracy of $0.2 \mathrm{~mm}-0.4 \mathrm{~mm}$ in concept modelling (Ryder et al., 2002). Consequently, the printing time for architectural models using RP technologies would normally be doubled compared to concept modelling (Ryder et al., 
have found that it was still very difficult to reproduce ornate details and free standing structures such as chimneys and railings. However, the accuracy of 3-D printing has been significantly improved over the past few years. For example, when used to print objects with medical applications (such as bone tissue engineering scaffolds), a printing accuracy at $\mu \mathrm{m}$ level could be expected. Melchels et al. (2010) reported that in biomedical engineering, stereolithography could print smallest feature at a size of $10-70 \mu \mathrm{m}$.

277

278

279

280

281

282

283

284

285

286

287

288

289

290

291

292

293

294

295

296

297

298

299

300

301

302

303

304

305

306

307

308

\subsection{3-D printing and entire building projects}

Due to the size of 3-D printers, it was argued that medium- or large-scale models or buildings might not be printed using 3-D printing technologies. However, there has been significant improvement in developing large-scale 3-D printers to meet the need of industrial-scale 3-D printing, especially in the recent few years. There were three major developments on the use of 3-D printing for printing entire buildings projects. In 2014, WinSun, one architectural company in China, has successfully printed a group of houses $\left(200 \mathrm{~m}^{2}\right.$ each) in Shanghai in less than a day. The size of the $3-D$ printer used in this project was $150 \mathrm{~m}$ (length) $\mathrm{x} 10 \mathrm{~m}$ (width) $\mathrm{x}$ 6.6m (height) which enabled it to print large-scale buildings within hours using high-grade cement and glass fibre (Hietzmann et al., 2015). With the inclusion of glass fibre, the strength and service life of the printed house were much better than those of common reinforced concrete (Liang and Liang, 2014). In 2015, one villa (approximately 1,100 square metres) and one five-storey apartment building were printed by the 3-D printer. The villa and apartment were not printed as one-piece. Instead, majority of the building elements were printed and brought to the site for installation. However, the project demonstrated the applicability of 3-D printing in printing entire building projects.

Qindao Unique Technology also demonstrated one large 3-D printer of a size about $12 \mathrm{~m} \times 12 \mathrm{~m}$ $\mathrm{x} 12 \mathrm{~m}$ in 2014. The printer used the FDM technology which deposit and stack the half-melt printing material from layer to layer. According to Liang and Liang (2014), the printer had a printing accuracy at millimetre level. Unlike the technology developed by WinSun, this 3-D printer used glass reinforced plastic as the printing material which could provide anti-corrosion, anti-aging and waterproof functions (Liang and Liang, 2014).

Another important milestone is that Amsterdam-based DUS Architects has developed its own 3-D printer of 6-metre tall (KamerMaker), which would later be used to fabricate a canal house. KamerMaker could use polypropylene as the printing material to produce components with dimensions of up to $2.2 \mathrm{~m} \times 2.2 \mathrm{~m} \times 3.5 \mathrm{~m}$ (Bogue, 2013). These components, as parts of the canal house, were later installed on site. The whole building project would be open to the public as a design museum, with 12 rooms dedicated to different types of 3-D printed building research (Rutkin, 2014). This project was expected to be completed in 2017. Table 2 summarizes the development of 3-D printing in the construction industry. 
310 Table 2. The development of 3-D printing in the construction industry

\begin{tabular}{|l|l|l|}
\hline Studies & $\begin{array}{l}\text { 3-D printing technology } \\
\text { presented }\end{array}$ & Printed products \\
\hline $\begin{array}{l}\text { Hinczewski et al. } \\
(1998)\end{array}$ & Stereolithography & Ceramic part \\
\hline $\begin{array}{l}\text { Khoshnevis et al. } \\
(2001)\end{array}$ & Contour Crafting & $\begin{array}{l}\text { Plaster part } \\
\text { Ceramic part }\end{array}$ \\
\hline Ryder et al. (2002) & Concept Modelling & Polyester part \\
\hline Lim et al. (2012) & Concrete Printing & Concrete part \\
\hline Gibson et al. (2002) & FDM and SLS & $\begin{array}{l}\text { Space frame architectural model } \\
\text { Rotunda architectural model } \\
\text { IBM Pavilion architectural model }\end{array}$ \\
\hline Dimitrove et al. (2006) & 3DP & Plaster model \\
\hline Bogue (2013) & KamerMaker & $\begin{array}{l}\text { Large-scale } \\
\text { components }\end{array}$ \\
\hline Kietzmann et al. (2015) & 3DP & Entire house \\
\hline Liang and Liang (2014) & FDM & Entire house \\
\hline
\end{tabular}

311

312 However, there are practitioners who have questioned the use of 3D printing to print entire 313 houses. For example, According to Platt Boyd, the developer of C-Fab, the construction 314 industry should minimize the use of 3D printing given the stability of the technology (Molitch315 Hou 2015). The C-Fab technology only prints the support structure of the wall. The technology 316 can be readily integrated into modern construction more quickly and affordably than the 317 traditional gantry-style printing, such as the gantry system used by WinSun.

\section{The challenges and future of 3-D printing in the construction industry} 3-D printing is not an isolated solution that can solve all the problems in the construction industry. There are several requirements, such as the scale of the project and printing materials, which should be fulfilled in order for the printing technology to perform at its maximum potential. These requirements will limit the use of 3-D printing in the construction industry. However, as technology is being improved to address the limits, the applicability of 3-D printing will be expanded accordingly.

\subsection{3-D printing and large-scale models or buildings}

326 There was a speculation that 3-D printing technologies, especially RP technologies, might not be well suited to building large landscape models or buildings (Gibson et al., 2002). Gibson et al. (2002) argued that most RP machines had a comparatively small build envelope for approximately $250 \mathrm{~mm}$ cubed. As such, the size of the printed model would be limited. Berman (2012) also argued that 3-D printing technology was most widely useful in applications with small part sizes. Many other researchers have also stated that the primary limitation of 3D printing technology was the size of the printer necessary to print the item (e.g. Campbell et al., 2011). 
The reasons leading to such speculation were twofold. As most 3-D printers were small when the technology trend started, it remained unclear whether the technology could be used to print large-scale models or buildings as the size of 3-D printers was directly related to the models or buildings it could print. However, in recent years, with the new development of 3-D printers, there have been a lot of large-scale models or buildings that were printed using large-scale 3D printers. For example, KarmerMaker in the canal house project was 6-m tall and the 3-D printer used by WinSun had a dimension of 150m x 10m x 6.6m (Liang and Liang, 2014).

In addition to the size of the printer, materials played a very important role in 3-D printing. The printing materials should have some basic features such as quick hardening in order to be used in 3-D printing. There were various studies which found that the strength and stability of the printed products using current printing materials (such as plaster) might prevent the technology from being used in large-scale models or buildings. For example, Khoshnevis et al. (2001) found that although plaster has been frequently used as printing material because it was commercially available, cheap, light in weight and quick hardening, the material demonstrated low wet-strength and a larger than 3 percent shrinkage. Similarly, although clay demonstrated a better wet-strength compared with plaster, the stability of the printed products has only been tested in small object sizes (Khoshnevis et al., 2001). The low availability of high-strength printing materials also led to the speculation that 3-D printing might not be used in large-scale models or buildings.

However, various materials have been modified and proved to be effective as high-strength printing materials recently. In order to be used as a printing material, concrete needed to have an acceptable degree of extrudability so that it can be extruded from the nozzle of the printer (Le et al., 2012). In addition, the concrete should bond together to form each layer and have sufficient buildability characteristics to enable it to lay down correctly, remain in position and be stiff enough to support further layers without collapsing (Le et al., 2012a). By changing the sand/binder proportions and the dosages of other admixtures in the mix design, a variety of compressive strength have been achieved, with the highest up to 107MPa (at 28 days) (Le et al., 2012b). As such, it is reasonable to assume that the strength of the printed concrete is strong enough to be used in high-rise residential or other large-scale building projects as concrete of 60-100MPa are normally used in these projects.

In 2014, WinSun claimed that by using 3-D printing technologies, a two-storey villa and a fivestorey apartment were printed. The projects demonstrate the applicability of 3-D printing in large-scale buildings, although many practical obstacles have been identified, including:

- Indirect process. Similar to precast concrete projects, construction components were printed in a closed factory, transported to the construction site and installed on site. As such, the villa and apartment were not printed directly from electronic data. Although it is very common to use joints when installing precast concrete components, such technology was not adopted in the printed villa and apartment. As can be seen from Figure 6, direct contact was often used. 
Figure 6. Connection details of the 3-D printed villa by WinSun.

- Brittleness. Although glass fibre was added to the printing concrete to increase the strength, the printing material was too brittle to be printed as load bearing components and construction components which span horizontally, such as slabs and staircases. When used in load bearing components, the material could be printed as moulds. As such, a great advantage of the technology is the elimination of de-moulding (see Figure 7). The problem was also found in the C-Fab printing process where the use of carbon fibre led to the brittleness of the printing material (Molitch-hou, 2015). 


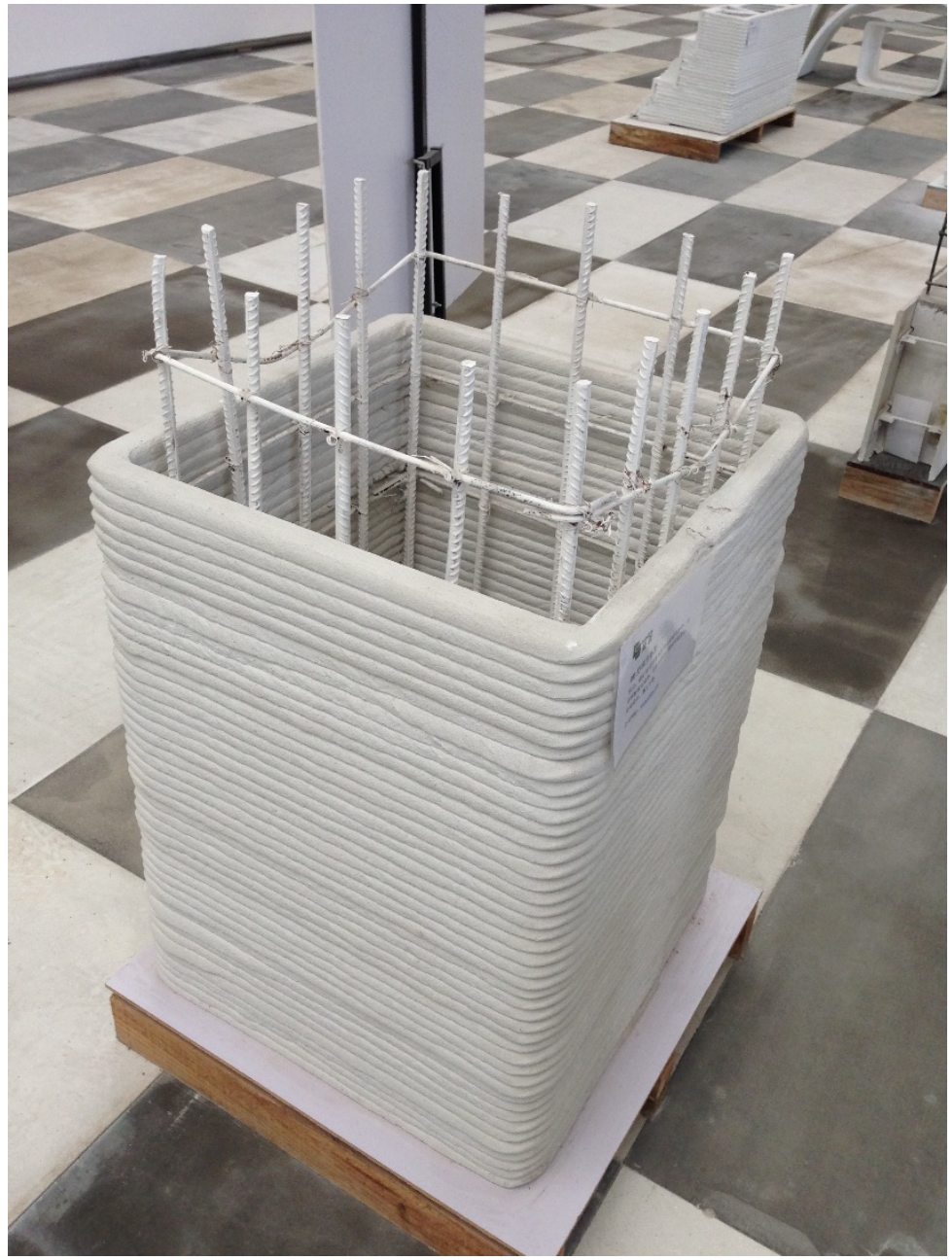

Figure 7. The concrete mould printed by WinSun.

- Exclusion of building services. Building services such as electrical and plumbing were not integrated in the 3-D printing process. Therefore, additional work had to be conducted, causing problems to the structural integrity. Figure 8 shows that electrical services were not integrated into the printing process and drilling was needed, which might cause potential damages. 


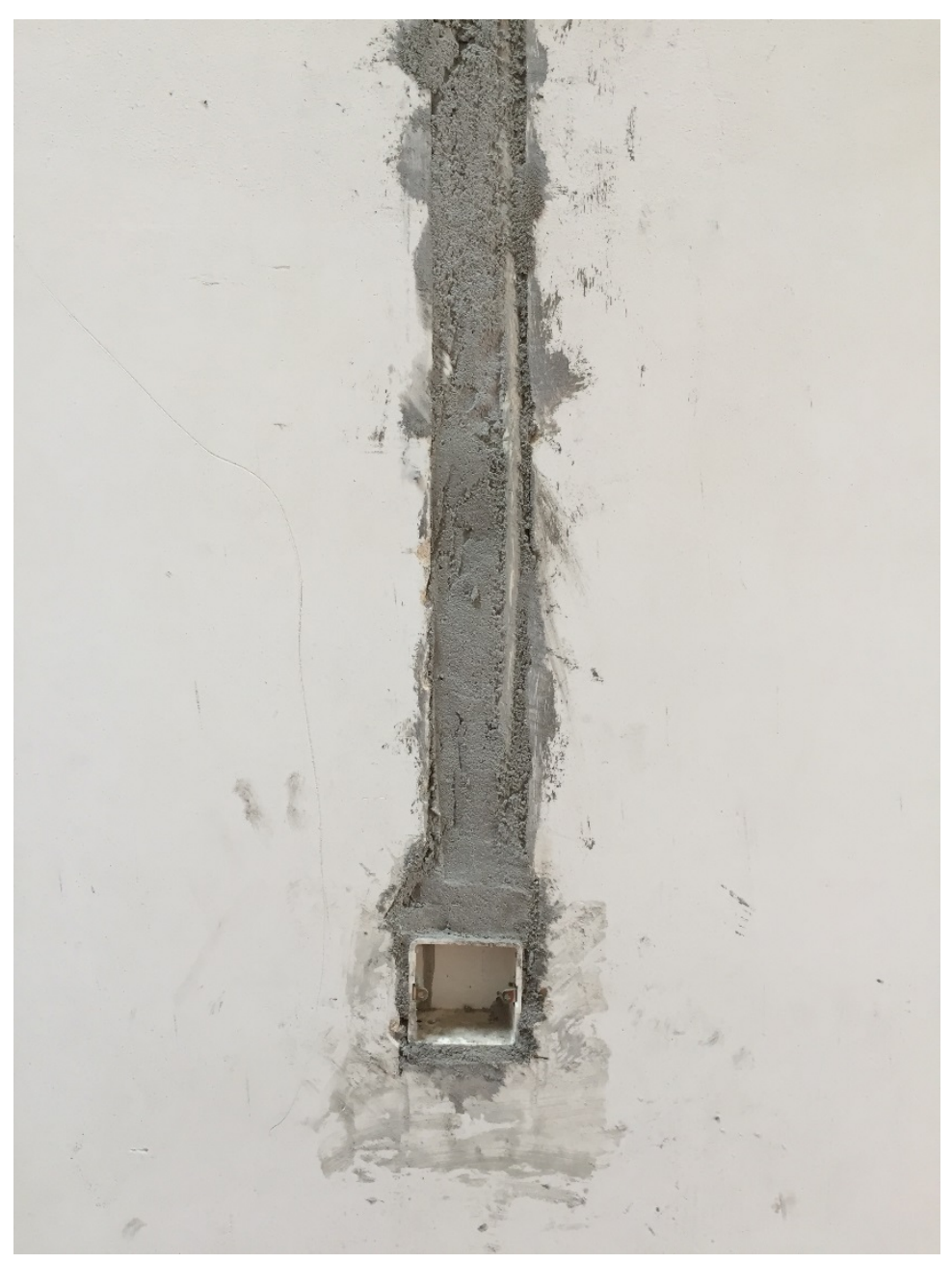

Figure 8. Electrical services are not integrated into the 3-D printing process by WinSun.

To summarize, 3D printing can be used to print large-scale buildings. However, there are lower demand of automated products in the construction industry when compared with other industries (Yossef and Chen, 2015). In addition, the materials (i.e. clay and concrete) need to be improved in terms of brittleness so that components which span horizontally can also be printed.

\subsection{3-D printing and building information modelling (BIM)}

According to Canessa et al. (2013), the process of 3-D printing that goes from an idea to a tangible object is quite long and complex, which contains six steps: digital modelling, exporting, slicing, connecting, printing, and finishing. While 2-D representations remain as the baseline method for project delivery in construction industry, substantial time is needed to create digital models for 3-D printing (Arayici et al., 2012). Traditional approaches of converting 2-D drawings to 3-D models encounter several issues including low accuracy, inefficiency and poor quality (Canessa et al., 2013). BIM is an emerging method for digital representation of physical and functional characteristics of a facility (Eastman et al., 2011). When compared with conventional 3-D modelling tools, BIM covers not only geometry information but material performance (i.e. yield strength, tensile strength, shear modulus, thermal conductivity, etc.), spatial relationships and manufacture information (Shou et al., 2014; Wang et al., 2014a). Furthermore, objects in BIM are defined as parameters and relations to other objects. As such, 
411 one object change will trigger related objects to be amended automatically (Eastman et al., 412 2011). In last five years, BIM has been proved as an effective method to facilitate 3-D printing 413 implementation in construction industry (Arayici et al., 2011; Arayici et al., 2012). BIM can 414 be used in the 3-D printing of small-scale models and large-scale buildings respectively.

415 Small-scale models are mainly used for finalized design representation and communication 416 (Sass and Oxman, 2006; Wang et al., 2014b). A major advantage of 3-D printing is its ability 417 to produce complex geometries such as internal passageways, undercuts and other features that 418 are difficult or even impossible to manufacture with conventional techniques (Bogue, 2013). 419 BIM is more powerful than conventional tools in complex building design (Chang and Shih, 420 2013). Interaction between 3-D printing and BIM enhances the ability to produce a small-scale 421 model rapidly from a BIM design without specialised or costly manufacturing equipment 422 (Bogue, 2013). Most of BIM tools support the exporting process of generating a file in proper 423 format (i.e. Standard Tessellation Language format) that can be directly converted into a set of 424 instructions for the print (Seo and Won, 2014). Furthermore, BIM vendors such as Autodesk 425 and Dassault System have collaborated with 3-D printing providers in order to further simplify 426 the process of 3-D printing from BIM models (Berman, 2012). For instance, users can online 427 print a real 3-D model by simply clicking the "Send to Sculpteo 3D Print", which has obvious 428 benefits in terms of time, cost and convenience (Laubner, 2011). 3-D printing-integrated BIM 429 supports the creative process of designers to produce variations of a single artefact or diverse 430 artefacts at various stages of design (Sass and Oxman 2006; Seo and Won 2014). In the 431 construction stage, complicated construction procedure can also be printed into small-scale 432 models from BIM so as to improve communication between designers and construction 433 contractors (Wei and Wen, 2012).

434 Due to size limitation of existing 3-D printers, it is difficult to print a high-rise building at a 435 time (Gibson et al., 2002). However, users can print structural components piece-by-piece and 436 then assemble them together as a real-scale building (Liang and Liang, 2014). When applying 437 this approach, users need to address two critical issues so that building as assemblages of 438 components reflects aspects of real-world material fabrication and assemble methods (Sass and 439 Oxman, 2006). The first issue is component design, which needs to comply with 3-D printer's 440 capability and raw-material performance (Sass and Oxman, 2006). BIM supports design 441 variations at component level and has been proved as an efficient tool to improve performance 442 of detailed design and fabrication design (Lu and Korman, 2010; Clevenger and Khan, 2013). 443 BIM provides a collaborative platform for different project participants to contribute their 444 expertise to optimize component design (Elmualim and Gilder, 2013). With BIM application, 445 each building component has the potential to be designed and printed as unique one. 446 Furthermore, the shapes of components designed in BIM can be assured to align to their 447 functional and structural attributes as an assembled model (Chi et al., 2015). In addition, 448 interaction between 3-D printing and BIM can significantly assist design changes and reduce 449 time of remodelling and reprinting. The second issue is related to assembly design, which is a 450 bottom up approach to design based on relationship between real-world construction and 451 abstract representation (Sass and Oxman, 2006). Components produced by 3-D printer need to 452 be tested in relationship to building scale constraints as individually produced objects, then as 
a complete assembly of objects (Sass and Oxman, 2006). BIM is an effective approach to simulate the overall assembly process and detect potential assembly issues before real printing (Zhang and $\mathrm{Hu}, 2011$; Chi et al., 2014). Interaction between 3-D printing and BIM gives new meaning to systematic ways of analysing connection strength, printing methods, and appearance.

Design for Manufacture and Assembly (DfMA) is an approach that emphasises the inclusion of manufacturing and assembly knowledge during the design phase (Lyon, 2011). This approach leads to simpler and more reliable products which are less expensive to assemble and manufacture (Boothroyd, 1994). In addition, any reduction in the number of parts in an assembly produces a snowball effect on cost reduction, because of the drawings, vendors, and inventory that are no longer needed (Boothroyd, 1994). DfMA tools encourage communications between designers, the manufacturing engineers and any other participants who have contributions to the final product.

In many manufacturing areas, DfMA has become an important approach in improving product development productivity through design (Barbosa and Carvalho, 2014). However, in the construction industry, building designers have not been provided with equivalent methodologies. The integration of construction knowledge into the design stages continues to rely on the experience of individuals in an increasingly fragmented work environment (Rekila et al., 2010). BIM has been considered as an effective tool for providing an integrated work environment, and is changing the building industry from design to maintenance phase (Wang et al., 2014b). The synergy between BIM and 3D-printing opens up new possibilities in applying DfMA to building industry. BIM can be used to provide an accurate 3-D integrated information model to foster building design and verify potential design and alternative designs from the 3-D printing perspective. In addition, BIM supports fabrication-level models which can be directly imported into 3-D printers and guide the printing process. By collaborating with manufacturing engineers, designers can also conduct a further analysis of the building's printability and assemblability, based on which potential design improvements can be made. In summary, BIM emergence leads to new opportunities for 3-D printing including design possibilities at the shape level as well as at performance and assembly levels.

\subsection{3-D printing and mass customization}

As discussed previously, one significant advantage of using 3-D printing was mass customization. The construction industry has always been considered as an industry with low degree of customization (Dubois and Gadde, 2000). For example, Cox and Thompson (1997) stated that the construction industry could be considered to be inherently a site specific and project based activity. As such, the survival of 3-D printing in the construction industry was also largely dependent on the degree of customisation requirements in the construction industry. A large demand for customisation would increase the demand for 3-D printed products, thus decreasing the printing costs and helping the technology survive in the construction industry. Therefore, the central issue was whether a large demand for mass customization could be expected in the construction industry. As Bardakci and Whitelock (2003) has pointed out, the driver for implementing mass customization should come from the market, rather than from the production capabilities of the firm. Based on the customer customisation sensitivity theory 
proposed by Bardakci and Whitelock (2003), the success of 3-D printing in the construction industry would be dependent on two tenets: the uniqueness of customer's needs and customer sacrifice gap.

The uniqueness of customer's needs was determined by the demand pattern for the product (Bardakci and Whitelock, 2003). According to Bardakci and Whitelock (2003), customers would only need customisation if the demand pattern was innovative. In the construction industry, some routine work, such as foundations, must inevitably be carried out on site. The demand pattern for these types of construction work would probably be functional rather than innovative. On the other hand, other types of construction work, such internal furnishings, may have high innovative demand and may be useful platforms for the 3-D printing technologies to reach its maximum potential. Previous studies have found that there was a demand for mass customization in the construction industry. For example, in the Korean construction industry, especially the house-building sector, mass customisation has become a key marketing strategy since the late 1990s (Kim et al., 2004). Contractors have paid more attention to provide individualized products to customers (Shin et al., 2008). Similarly, construction companies in Japan (e.g. Sikisui House) have also started to use IT-based flexible planning system to provide a high degree of customization to buyers (Gann, 1996). However, the categorization of demands in the construction industry (i.e. either functional or innovative) requires further investigation. Similarly, future research is needed to identify the customer sacrifice gap, i.e. the gap between the desired product and available products in the construction market. As customization options were usually limited by suppliers in order to achieve economies of scale in the construction process, knowing the categorization of demands, the degree of these demands and the customer sacrifice gap will be useful for 3-D printing technology to reach economies of scale.

\subsection{3-D printing and life cycle costing}

According to Noguchi (2003), prefabricated homes in Japan were approximately 8\% more expensive than their site-built counterparts. One central issue that will affect the implementation of 3-D printing in the construction industry is whether it could lead to cost increase or cost reduction, as the industry remains cost sensitive (Rajeh et al., 2015). Although there were 3-D printed houses at the time of the study, these cases have yet been empirically studied. It remained unclear whether 3-D printing could lead to reduced or increased construction cost, although many news websites and weblogs (e.g. www.3ders.org) have reported that 3-D printing can lead to reduced construction costs. For example, the printed house (approximately 200 square metres) by WinSun in Shanghai cost 30,000RMB (\$4,800 equivalent), which was far less than the cost using traditional construction technology.

The commonly recognized three cost items in construction included labour, material and plant. Advocators argued that as the 3-D printing process was an automated process that was centrally operated by computer, the requirement of manpower could be greatly reduced (Buswell et al., 2006). However, Buswell et al. (2006) also demonstrated that the production of a wall structure using 3-D printing technology was prohibitively expensive due to the use of current printing materials which were usually more expensive. On the other hand, for completed structures (such as highly serviced walls with the installation of multiple electrical conduits), using 3-D 
printing technology could bring cost reduction in terms of optimized site work and reduced remedial works. According to Le et al., (2012), the integration of mechanical and electrical services in the 3-D printing process could optimize materials usage and site work, thus leading to reduced likelihood of costly remedial works. The cost of 3-D printing should also include the cost of 3-D printers. The price of 3-D printers has been reduced significantly over the years and private individuals in the developed world may easily own one (Bradshaw et al., 2010). It should be noted that certain software packages were needed to edit and compile the source code in order to print the architectural models or large-scale houses. These proprietary software packages would increase the cost of the 3-D printer package, thus restricting the scaling of the 3-D printing technology (Pearce et al., 2010). In summary, although short-term potential cost reduction can be achieved by $3-\mathrm{D}$ printing, empirical studies are needed to investigate the financial performance of the printed construction product or project over its life cycle.

\section{Conclusions}

3-D printing, as an automated layer-by-layer production process, is a promising technology that can be used by the construction industry to achieve economic, environmental and other benefits. The use of 3-D printing in the construction industry is highly dependent on the accuracy of the printing jobs, the availability of printing materials, the cost of the printing process and printing time, based on which relevant 3-D printing technologies, including stereolighography, fused deposition modelling, inkjet powder printing, selective laser sintering, selective heating sintering and contour crafting, can be chosen. While selective laser sintering can be used to print metal-based objectives, contour crafting can be used to print cementitious and ceramics products. Various benefits such as reduced waste, design flexibility and reduced manpower have been recorded.

However, the use of 3-D printing is also subject to a few prerequisite requirements, mainly on applicability in large-scale building projects, the development of building information modelling, the degree of requirements on mass customization and the life cycle cost of 3-D printed construction products/projects. As the use of 3-D printing in the construction industry is still in its infancy, the life cycle performance of the printed projects remains unclear, although the use of BIM can help examine the printed products at the shape level as well as at the performance and assembly levels. In addition, the categorization and the degree of customisation have yet been empirically examined in the construction industry. It is expected that by addressing these challenges, 3-D printing can reach its maximum potential in the construction industry.

\section{References}

571 Abdel-Wahab, M.S., Dainty, A.R.J., Ison, S.G., Bowen, P. and Hazlehurst, G. Trends of skills 572 and productivity in the UK construction industry. Engineering, Construction and Architectural 573 Management 2008; 15(4):372-382. discharge machining electrodes. Rapid Prototyping Journal 1996; 2(1):4-12. 

implementation for architectural practices. Structural survey 2011; 29(1): 7-25.

578

579

580

581

582

583

584

585

586

587

588

589

590

591

592

593

594

595

596

597

598

599

600

601

602

603

604

605

606

607

608

609

610

Arayici, Y., C. Egbu and P. Coates. Building information modelling (BIM) implementation and remote construction projects: issues, challenges, and critiques. Journal of Information Technology in Construction 2012; 17: 75-92.

Bak, D. Rapid prototyping or rapid production? 3D printing processes move industry towards the latter. Assembly Automation 2003; 23(4):340-345.

Barbosa, G. and J. Carvalho, Guideline tool based on design for manufacturing and assembly (DFMA) methodology for application on design and manufacturing of aircrafts. Journal of the Brazilian Society of Mechanical Sciences and Engineering, 2014. 36(3): p. 605-614.

Bardakci, A. and Whitelock, J. Mass-customization in marketing: the consumer perspective. Journal of Consumer Marketing 2003; 20(5): 463-479.

Barlow, J., Childerhouse, P., Gann, D., Hong-Minh, S., Naim, M. and Ozaki, R. Choice and delivery in housebuilding: lessons from Japan for UK housebuilders. Building Research \& Information 2003; 31(2): 134-145.

Berman, B. 3-D printing: the new industrial revolution. Business Horizons 2012; 55(2):155162.

Bogue, R. 3D printing: the dawn of a new era in manufacturing. Assembly Automation 2013; 33(4): 307-311.

Boothroyd, G., Product design for manufacture and assembly. Computer-Aided Design, 1994. 26(7): p. 505-520.

Bradshaw, S., Bowyer, A. and Haufe, P. The intellectual property implications of low-cost 3D printing. ScriptEd 2010; 7(1):5-31.

Buswell, R.A., Soar, R.C., Gibb, A.G.F. and Thorpe, A. Freeform construction: mega-scale rapid manufacturing for construction. Automation in Construction 2006; 16:224-231.

Butscher, A., Bohner, M., Hofmann, S., Gauckler, L. and Müller, R. Structural and material approaches to bone tissue engineering in powder-based three-dimensional printing. Acta Biomaterialia 2011; 7(3):907-920.

Campbell, T., Williams, C., Ivanova, O., Garrett, B. Could 3D printing change the world: technologies, potential, and implications of additive manufacturing. Atlantic Council: Washington, 2011.

Canessa, E., Fonda, C., and Zennaron, M., eds. Low-Cost 3D printing for science, education sustainable development. Trieste: ICTP - The Abdus Salam International Centre for Theroretical Physics 2013.

Casey, L. Prototype pronto. Packaging Digest 2009; 46(8):554-56. 
611 Castrejon-Pita, J.R., Baxter, W.R.S., Morgan, J., Temple, S., Martin, G.D. and Hutchings, I.M.

612 Future, opportunities and challenges of Inkjet technologies. Atomization and Sprays 2013;

613 23:541-565.

614 Chang, Y.-F. and S.-G. Shih. BIM-based Computer-Aided Architectural Design. Computer615 Aided Design and Applications 2013; 10(1): 97-109.

616 Chi, H.-L., J. Wang, X. Wang, M. Truijens and P. Yung. A Conceptual Framework of Quality617 Assured Fabrication, Delivery and Installation Processes for Liquefied Natural Gas (LNG)

618 Plant Construction. Journal of Intelligent \& Robotic Systems 2014; 1-16.

619 Chi, H.-L., X. Wang and Y. Jiao. BIM-Enabled Structural Design: Impacts and Future 620 Developments in Structural Modelling, Analysis and Optimisation Processes. Archives of 621 Computational Methods in Engineering 2015; 22(1): 135-151.

622 Clevenger, C. M. and R. Khan. Impact of BIM-enabled design-to-fabrication on building 623 delivery. Practice Periodical on Structural Design and Construction 2013; 19(1): 122-128.

624 Cox, A. and Thompson, I. "Fit for purpose" contractual relations: determining a theoretical 625 framework for construction projects. European Journal of Purchasing and Supply Management 626 1997; 3:127-135.

627 Laubner, D. Use 3DVIA to Make a 3D Print of Your 3D Models Today. 2011. Available from: 628 http://www.3dvia.com/blog/use-3dvia-to-make-a-3d-print-of-your-3d-models-today/ (cited 18 629 Oct 2014).

630 De Gans, B.-J., Duineveld, P.C. and Schubert, U.S. Inkjet printing of polymers: state of the art 631 and future developments. Advanced Materials 2004; 16(3):203-213.

632 Dubois, A. and Gadde, L.E. Supply strategy and network effects - purchasing behaviour in the 633 construction industry. European Journal of Purchasing \& Supply Management 2000; 6(3634 4):207-215.

635 Eastman, C., P. Teicholz, R. Sacks and K. Liston. BIM handbook: A guide to building 636 information modeling for owners, managers, designers, engineers and contractors, John Wiley 637 \& Sons: 2011.

638 Elmualim, A. and J. Gilder. BIM: innovation in design management, influence and challenges 639 of implementation." Architectural Engineering and Design Management 2013; 10(3-4): 183640199.

641 Gan, D.M. Construction as a manufacturing process? Similarities and differences between 642 industrialized housing and car production in Japan. Construction Management and Economics 643 1996; 14:437-450.

644 Gibson I., Kvan, T. and Ming, L.W. Rapid prototyping for architectural models. Rapid 645 Prototyping Journal 2002; 8(2):91-95 
646 Harty, C. Implementing innovation in construction: contexts, relative boundedness and actor-

647 network theory. Construction Management and Economics 2008; 26(10):1029-1041.

648 Hinczewski, C., Corbel, S. and Chartier, T. Stereolithography for the fabrication of ceramic 649 three-dimensional parts. Rapid Prototyping Journal 1998; 4(3):104-111.

650 Hull, C.W. Apparatus for production of three-dimensional objects by stereolithography. US 651 Patent 4575330 A, 1986.

652 Kamrani, A.K. and Nasr, E.A. Engineering design and rapid prototyping. Springer US: Boston, 653 MA; 2010.

654 Kang, H.W. and Cho, D.W. Development of an indirect stereolithography technology for 655 scaffold fabrication with a wide range of biomaterial selectivity. Tissue Engineering Part C 656 Methods 2012; 18(9):719-729.

657 Khoshnevis, B., Russell, R., Kwon, H. and Bukkapatnam, S. Contour crafting - a layered 658 fabrication technology. Special Issue of IEEE Robotics and Automation Magazine 2001; 659 8(3):33-42.

660 Khoshnevis, S., Bukkapatnam, S., Kown, H. and Saito, J. Experimental investigation of 661 contour crafting using ceramics materials. Rapid Prototyping Journal 2001; 7(1):32-41.

662 Khoshnevis, B. Automated construction by contour crafting - related robotics and information 663 technologies. Automation in Construction 2004; 13(1):5-19.

664 Kim, Y.S., Oh, Y.K. and Kim, J.J. A planning model for apartment development project 665 reflecting client requirements. Korea Journal of Construction Engineering and Management 666 2004, 5(3):88-96.

667 Kimitrov, D., Schreve, K. and De-Beer, N. Advances in three dimensional printing - state of 668 the art and future perspectives. Journal of New Generation Sciences 2006; 4(1): 21-49.

669 Kietzmann, J., Pitt, L. and Berthon, P. Disruptions, decisions and destinations: entre the age of 670 3-D printing and additive manufacturing. Business Horizons 2015; 58(2):209-215.

671 Klotz, I., Horman, M. and Bodenschatz, M. A lean modelling protocol for evaluating green 672 project delivery. Lean Construction Journal 2007; 3(1):1-18.

673 Kreiger, M.A., MacAllister, B.A., Wilhoit, J.M. and Case, M.P. The current state of 3D printing 674 for use in construction. . In: the Proceedings of the 2015 Conference on Autonomous and 675 Robotic Construction of Infrastructure. Ames. Iowa, 149-158.

676 Kruth, J-P., Froyen, L., Vaerenbergh, J.Van., Mercelis, P., Rombouts, M. and Lauwers, B. 677 Selective laser melting of iron-based powder. Journal of Materials Processing Technology 678 2004; 149(1-3):616-622.

679 Kruth, J-P., Mercelis, P. and Vaerenbergh, J.Van. Binding mechanisms in selective laser 680 sintering and selective laser melting. Rapid Prototyping Journal 2005; 11(1): 26-36. 
681 Liang, F. and Liang, Y. Study on the status quo and problems of 3D printed buildings in China.

682 Global Journal of Human-Social Science 2014; 14(5):7-10.

683 Le, T.T., Austin, S.A., Lim, S., Buswell, R.A., Gibb, A.G.F., Thorpe, T. Mix design and fresh 684 properties for high-performance printing concrete. Materials and Structures 2012a; 45:12216851232.

686 Le, T.T., Austin, S.A., Lim, S., Buswell, R.A., Gibb, A.G.F., Thorpe, T. Hardened properties 687 of high-performance printing concrete. Cement and Concrete Research 2012b; 42(3):558-566.

688 Lim, E.C. and Alum, J. Construction productivity: issues encountered by contractors in 689 Singapore. International Journal of Project Management 1995; 13(1):51-58.

690 Lim, S., Buswell, R.A., Le, T.T., Austin, S.A., Gibb, A.G.F. and Thorpe, T. Developments in 691 construction-scale additive manufacturing processes. Automation in Construction 2012; $692 \quad 21: 262-268$.

693 Lo, T., Fung, I. and Tung, K. Construction delays in Hong Kong civil engineering projects. 694 Journal of Construction Engineering and Management 2006; 132(6):636-649.

695 Lu, N. and T. Korman. Implementation of building information modeling (BIM) in modular 696 construction: Benefits and challenges. Proceedings of the Construction Research Congress, 697 Banff, Alta. 2010.

698 Lyon, E., Emergence and Convergence of Knowledge in Building Production: Knowledge699 Based Design and Digital Manufacturing, in Distributed Intelligence in Design. 2011, Wiley$700 \quad$ Blackwell. p. 71-98.

701 Melchels, F.P.W., Feijen, J., Grijpma, D.W. A review on stereolithography and its applications 702 in biomedical engineering. Biomaterials 2010; 31(24):6121-6130.

703 Mireles, J., Espalin, D., Roberson, D., Zinniel, B., Medina, F. and Wicker, R. Fused deposition 704 modelling of metals. In: Proceedings of Solid freeform Fabrication Symposium 2012, pp.836705845.

706 MIT. Three dimensional printing: any composition, any material and any geometry. 2000. 707 http://www.mit.edu/ tdp/whatis3dp.html (cited 06 Mar 2015)

708 Molitch-hou, M. Brach technology is 3D printing the future of construction one wall at a time. 709 2015. http://3dprintingindustry.com/2015/07/28/branch-technology-is-3d-printing-the-future710 of-construction-one-wall-at-a-time/ (cited 10 Jan 2016)

711 Monolite. D-Shape. 2015. http://www.d-shape.com/cose.htm (cited 10 Jan 2016)

712 Nasir, H., Ahmed, H., Hass, C. and Goodrum, P.M. An analysis of construction productivity 713 differences between Canada and the United States. Construction Management and Economics 714 2014; 32(6):595-607. 
715 Noguchi, M. The effect of the quality-oriented production approach on the delivery of

716 prefabricated homes in Japan. Journal of Housing and Built Environment 2003; 18:353-364.

717 Pearce, J.M., Blair, C.M., Laciak, K.J., Andrews, R., Nosrat, A. and Zelenika-Zovko, I. 3-D 718 printing of open source appropriate technologies for self-directed sustainable development. 719 Journal of Sustainable Development 2010; 3(4): 17-29.

720 Rajeh, M., Tookey, J.E. and Rotimi, J.O.B. Estimating transaction costs in the New Zealand 721 construction procurement: a structural equation modelling methodology. Engineering, 722 Construction and Architectural Management 2015; 22(2):242-267.

723 Rekola, M., J. Kojima, and T. Mäkeläinen, Towards Integrated Design and Delivery Solutions: 724 Pinpointed Challenges of Process Change. Architectural Engineering and Design Management, 725 2010. 6(4): p. 264-278.

726 Rutkin, A. Watch as the world's first 3D-printed house goes up. New Scientist 2014; 727 221(2960):24.

728 Sass, L. and R. Oxman. Materializing design: the implications of rapid prototyping in digital 729 design. Design Studies 2006; 27(3): 325-355.

730 Seo, D. and H. Won. A Basic Study on Korean-style House Model Manufacturing with 3D 731 Laser Printer Based on BIM (Building Information Modeling). Advanced Science and 732 Technology Letters 2014; 47 ((Architecture and Civil Engineering 2014), 21-24.

733 Shin, Y., An, S.H., Cho, H.H., Kim, G.H. and Kang, K.Y. Application of information 734 technology for mass customization in the housing construction industry in Korea. Automation 735 in Construction 2008; 17(7):831-838.

736 Shou, W., J. Wang, X. Wang and H. Y. Chong. A Comparative Review of Building Information 737 Modelling Implementation in Building and Infrastructure Industries. Archives of 738 Computational Methods in Engineering 2014; 1-18.

739 TechNavio. Global 3D printing materials market 2014-2018. 2014. Available from: 740 http://www.technavio.com/report/global-3d-printing-materials-market-2014-2018 (cited 18 741 Oct 2014)

742 Tidd, J., Bessant, J. and Pavitt, K. Managing innovation integrating technological, market and 743 organizational change. John Wiley and Sons, Chichester: 1997.

744 Vinodh, S., Sundararaj, G., Devadasan, S.R., Kuttalingam, D. and Rajanayagam, D. Agility 745 through rapid prototyping technology in a manufacturing environment using a 3D printer. 746 Journal of Manufacturing Technology Management 2009; 20(7):1023-1041.

747 Wang, J., W. Sun, W. Shou, X. Wang, C. Wu, H.-Y. Chong, Y. Liu and C. Sun. Integrating 748 BIM and LiDAR for Real-Time Construction Quality Control. Journal of Intelligent \& Robotic 749 Systems 2014a; 1-16. 
750 Wang, J., X. Wang, W. Shou and B. Xu. Integrating BIM and augmented reality for interactive 751 architectural visualisation. Construction Innovation 2014b; 14(4): 453-476.

752 Wei, C. and Q. Wen. On Rapid Prototyping Instrument Applied in BIM Technology. China 753 Municipal Engineering 2012; 6: 026.

754 Wu, P. and Low, S.P. Managing the embodied carbon of precast concrete columns. Journal of 755 Materials in Civil Engineering 2011; 23(8): 1192-1199.

756 Yossef, M. and Chen, A. Applicability and limitations of 3D printing for civil structures. In: 757 the Proceedings of the 2015 Conference on Autonomous and Robotic Construction of 758 Infrastructure. Ames. Iowa, 237-246.

759 Zhang, J. and Z. Hu. BIM-and 4D-based integrated solution of analysis and management for 760 conflicts and structural safety problems during construction: 1. Principles and methodologies. 761 Automation in construction 2011; 20(2): 155-166. 